\title{
ASSESSMENT OF REAGENT EFFECTIVENESS AND PRESERVATION METHODS FOR EQUINE FAECAL SAMPLES
}

\author{
Eva Vavrouchova, Stepan Bodecek, Olga Dobesova \\ University of Veterinary and Pharmaceutical Sciences, \\ Faculty of Veterinary Medicine, Equine Clinic, Brno, Czech Republic
}

Received 9 October 2014; Received in revised form 6 January 2015; Accepted 22 January 2015

\begin{abstract}
The aim of our study was to identify the most suitable flotation solution and effective preservation method for the examination of equine faeces samples using the FLOTAC technique. Samples from naturally infected horses were transported to the laboratory and analysed accordingly. The sample from each horse was homogenized and divided into four parts: one was frozen, another two were preserved in different reagents such as sodium acetate-acetic-acid-formalin(SAF) or 5\% formalin. The last part was examined as a fresh sample in three different flotation solutions (Sheather's solution, sodium chloride and sodium nitrate solution, all with a specific gravity 1.200). The preserved samples were examined in the period from 14 to 21 days after collection. According to our results, the sucrose solution was the most suitable flotation solution for fresh samples (small strongyle egg per gram was 706 compared to 360 in sodium chlorid and 507 in sodium nitrate) and the sodium nitrate solution was the most efficient for the preserved samples (egg per gram was 382 compared to 295 in salt solution and 305 in sucrose solution). Freezing appears to be the most effective method of sample preservation, resulting in minimal damage to fragile strongyle eggs and therefore it is the most simple and effective preservation method for the examination of large numbers of faecal samples without the necessity of examining them all within 48 hours of collection. Deep freezing as a preservation method for equine faeces samples has not, according to our knowledge, been yet published.
\end{abstract}

Key words: horse, flotation solution, small strongyles, freezing, formalin

\section{INTRODUCTION}

The FLOTAC technique was developed as a new multivalent copromicroscopic technique for veterinarians and was then adapted for human parasitology (1). The apparatus, three FLOTAC techniques and types of reagents are described in detail elsewhere (2). The FLOTAC technique allows quantification of eggs and larvae of nematodes, trematodes and cysts or oocysts of intestinal protozoa in as little as 1 gram of faeces.

Many papers have compared the FLOTAC technique with the standard Kato-Katz (3-5)

Corresponding author: Dr. Štěpán Bodeček, $\mathrm{PhD}$

E-mail address: bodeceks@vfu.cz

Present address: Equine Clinic, Faculty of Veterinary Medicine

University of Veterinary and Pharmaceutical Sciences Brno

Palackého 1/3, 61242 Brno, Czech Republic

Phone: +420 725740479

Copyright: (C) 2015 Vavrouchova E. This is an open-access article published under the terms of the Creative Commons Attribution License which permits unrestricted use, distribution, and reproduction in any medium, provided the original author and source are credited. Competing Interests: The authors have declared that no competing interests exist.

Available Online First: 13 February 2015

http://dx.doi.org/10.14432/j.macvetrev.2015.02.040 and the ether concentration method used in human parasitology. The FLOTAC technique has superior diagnostic sensitivity when compared to multiple Kato-Katz thick smears and to the ether concentration method $(2,6)$, especially for samples with a lower EPG (eggs per gram) content.

FLOTAC techniques have also been successfully used for the diagnosis of Aelurostrongylus abstrusus larvae in cats (7), Crenosoma vulpis (8), Ancylostoma caninum (9), Angiostrongylus vasorum (10) in canine faecal samples and Dicrocoelium dendriticum (11) in sheep, as well as produced promising results for the diagnosis of pinworm in rabbits (12) and whipworm infection in simians (13).

Many factors may influence the performance of FLOTAC such as parasitic elements, flotation solutions and different methods of faecal preservation. Several preservation methods including freezing, $10 \%$ and $5 \%$ formalin, modified PVA (polyvinylchloride alcohol) and special commercial reagents such as SAF (sodium acetateacetic acid formalin), Ecofix, Parasafe, Proto-fix, STF (streck tissue fixative) are used in parasitology 
(14). The majority of published articles describe preservation with formalin or SAF rather than freezing which can damage fragile eggs.

Experience has shown that the use of fresh faeces produces the most accurate results, but FLOTAC techniques can be performed on faeces stored for 1-3 days at $4^{\circ} \mathrm{C}$ and on preserved faecal samples stored in 5 or $10 \%$ formalin or SAF for several weeks or months (1). Five percent formalin produced more accurate results than other faecal preservatives (1). Sheather's solution, saturated sodium chloride, sodium nitrate $\left(\mathrm{NaNO}_{3}\right)$ and Rinaldi's solution (sucrose and potassium iodomercurate) were recommended in Cringoli's article for the assessment of common intestinal parasites in horses.

\section{MATERIAL AND METHODS}

Based on our previous screening of several farms in South Moravia, the selection of a proper breeding farm for this study was made according to the number of horses available, good cooperation with owners, more than 200 egg per gram (EPG) count for strongyles by McMaster and the anticipated occurrence of Parascaris equorum in young horses. Twenty naturally infected horses were included in the study. The young horses were pastured together, whereas the adults were stabled in individual boxes and weanlings were group housed.

Twenty fresh samples were collected in January 2012 (17 samples from adults and three from weanlings born the previous spring). Each sample was individually packed and numbered. Samples were immediately transported to the laboratory where they were homogenized using a manual mixing from a larger faecal sample, weighed and either prepared for immediate use, or preserved by freezing or placed in an appropriate reagent. For preservation by freezing, $10 \mathrm{~g}$ were removed and placed in plastic tubes in a deep freezer $\left(-80^{\circ} \mathrm{C}\right)$. Samples which were intended for preservation in different reagents (SAF or 5\% formalin), one gram was removed and added to $10 \mathrm{ml}$ of the preservative solution. Tubes with samples preserved in reagent were stored in a fridge $\left(4^{\circ} \mathrm{C}\right)$ for period 14 to 21 days before examination.

The three flotation solutions (Sheather's solution, sodium chloride and sodium nitrate, all with specific gravity 1.200) selected for use in our study were the most efficient according to a previous study of strongyle, Parascaris equorum and Anoplocehpala perfoliata egg detection in horses. They were prepared using the standard methods (1). Sodium chloride solution was identified as the least 102 suitable for the fresh samples as it gave the lowest EPG count and therefore was eliminated from further processing. The remaining two flotation solutions (Sheather's and sodium nitrate) were used for examination of preserved samples.

Fresh, defrosted (in laboratory temperature $20^{\circ} \mathrm{C}$ ) and reagent preserved samples were placed in the FLOTAC ${ }^{\circledR}$ which permits a maximum magnification of 400. The FLOTAC double technique which is based on simultaneous examination of two different faecal samples from two different hosts using a single FLOTAC apparatus was used (1).

\section{Statistical analysis}

A linear regression model was selected to assess any relationship within the data due to the low number of samples and character of the data. Initially a suitable method had to be chosen to modify the data prior to the use of the linear regression model. This was carried out in accordance with the principle "round-robin" and by obtaining comparative data. This method was based on descriptive statistics and correlation coefficients. Subsequently, metric values were used to compare the different flotac media and to indentify the most suitable.

The input data consisted of twenty independent samples in four separate files (a separate file for fresh samples, frozen samples and samples preserved in $5 \%$ formalin or SAF). Each of these files contained a triplet of independent measurements for every sample which differed only in the reagent used. Files for $5 \%$ formalin and SAF preservation contained only data recorded using the sodium nitrate or Sheather's flotation solutions.

\section{RESULTS}

\section{Examination of fresh samples}

All the faeces samples were positive for strongyle eggs and three samples $(13,14,15)$ were positive for Parascaris equorum eggs. The most efficient flotation reagent for detection of strongyle eggs and Parascaris equorum in fresh samples was Sheather's solution (s. g. 1.200). In comparison with sodium chloride (s. g. 1.200) and sodium nitrate (s.g. 1.200), the EPG values in the Sheather's solution were higher in 17 cases $(85 \%$, the exceptions being samples No. 1, 2 and 12).

\section{Frozen samples}

A different situation was found in the defrosted samples. Half of the samples $(10 ; 50 \%)$ had the highest strongyle EPG values when floated in a sodium nitrate solution, whilst eight samples (40\%) had the highest EPG values in Sheather's solution 
Reagent effectiveness and preservation methods for equine faecal samples

and two samples $(10 \%)$ in a salt solution. The salt solution was shown to be the least suitable and was thus eliminated from the next procedure.

\section{Preserved samples}

A higher strongyle EPG value was found in samples preserved in 5\% formalin and floated in a sodium nitrate solution (15 cases, $75 \%$ ) than in Sheather's solution (only five cases, 25\%). From the samples which had been preserved in a SAF reagent, $7(37 \%)$ had a higher EPG in a sodium nitrate solution. In ten samples $(50 \%)$, the results from both solutions (sodium nitrate and Sheather's) were comparable. from $-80^{\circ} \mathrm{C}$ and in each of the different flotation solutions showed a higher faecal egg count when compared with those from the two preservation reagents. In seven cases $(35 \%)$ the values of EPG were higher than from fresh samples in sodium nitrate solution and in three cases $(15 \%)$ higher than those in fresh samples floated in Sheather's solution.

Eggs of Parascaris equorum were least visible after preservation in SAF, while after freezing and preservation in 5\% formalin, the number of eggs had decreased to approximately one third of that in the fresh samples floated in Sheather's solution. When samples were floated in sodium nitrate solution, the

Table 1. Value of roundworms egg per gram in three positives samples



$\mathrm{NaCl}$ - sodium chloride, $\mathrm{SAF}$ - sodium acetate-acetic acid formalin, $\mathrm{NaNO}_{3}$ - sodium nitrate solution

\section{Flotation reagent}

Sodium nitrate was shown to be the most suitable flotation reagent for preserved samples. Values of small strongyle EPG were higher than in the Sheather's solution for all methods of preservation, not only with respect to the average and median values, but also for the maximum and minimum values.

\section{Comparison}

The most suitable preservation method in our study appeared to be freezing. Samples defrosted
EPG value for Parascaris equorum eggs showed no correlation with fresh, frozen or samples preserved in $5 \%$ formalin (Table 1).

\section{Summary}

Descriptive statistic analysis of this data, i.e. average, variance, median, minimum and maximum values are contained in Table 2 for each flotation solution and for each preservation method.

The average value of recorded eggs in the file for fresh samples could be considered as the natural base for distinguishing the capability of flotation

Table 2. Summary characteristics of small strongyle egg per gram values in correlation with preservation method and flotation solution

\begin{tabular}{lccccccccc}
\hline \multicolumn{1}{c}{ S.C. } & \multicolumn{3}{c}{ Fresh samples } & \multicolumn{5}{c}{ Formalin } & \multicolumn{2}{c}{ SAF } \\
\hline & $\mathrm{NaCl}$ & $\mathrm{NaNO}_{3}$ & Sheather's & $\mathrm{NaNO}_{3}$ & Sheather's & $\mathrm{NaNO}_{3}$ & Sheather's & $\mathrm{NaNO}_{3}$ & Sucrose \\
Average & 360.35 & 506.0 & 706.00 & 382.150 & 304.95 & 221.30 & 139.85 & 54.90 & 40.20 \\
Median & 297.00 & 525.00 & 570.00 & 263.00 & 239.00 & 147.00 & 120.00 & 35.00 & 25.00 \\
Min & 20.00 & 112.00 & 6.00 & 72.00 & 61.00 & 26.00 & 20.00 & 0.00 & 0.00 \\
Max & 868.00 & 994.00 & 2320.00 & 1346.00 & 1088.00 & 1088.00 & 442.00 & 232.00 & 148.00 \\
SD & 253.95 & 290.13 & 547.67 & 336.60 & 233.76 & 245.60 & 121.67 & 59.74 & 42.25 \\
\hline
\end{tabular}


solutions, but only with the assumption that data from one sample had the same EPG value in all three flotation solutions. The presumption is unrealistic because of the relatively uneven distribution of eggs in a sample and therefore the frequency is affected by the location in the faeces. The different input information produces significant errors and makes direct comparison of results impossible without previous modification. We tried to limit this problem by using homogenization.

It is possible to assess if there is any relationship between flotation solutions within one preservation method according to the correlation matrix (Table 2). Correlation coefficients for different preservation methods for the same flotation solution did not indicate any linear relationship. Relative dispersion of EPG in fresh, frozen and preserved samples is described by the coefficient of variation in Figure 1. solution for faecal suspension and method of faecal preservation which affects the results.

According to our results the most efficient reagent for fresh samples was Sheather's solution with regards to strongyle eggs. Values of EPG for Parascaris equorum were comparable in all three reagents. Another publication presented sodium chloride and Rinaldi's solutions as the most efficient for strongyles, sodium nitrate and Rinaldi's solution for Parascaris equorum and sucrose solution for Anoplocephala spp. (1). Our results were different as we obtained the lowest faecal count for strongyle eggs from sodium chloride solution. Rinaldi's solution is based on the use of mercury iodide which is toxic and dangerous for the environment and therefore a safety cabinet must be used and special waste control is required (1). This was the reason for replacing it with different flotation solutions in our study.



Figure 1. Correlation between value of small strongyle egg per gram and preserved method in different flotation solution. 1 - sodium chloride solution, 2 - sodium nitrate solution, 3 - Sheather's solution

\section{DISCUSSION}

The aims of this study were to identify the most efficient flotation solution for quantifying equine parasites using the FLOTAC technique; to identify the most suitable method for preservation of samples and to investigate whether the results obtained from different methods are comparable. We attempted to compare the flotac solutions recommended in the literature (1). Previously we have used a saturated sodium chloride solution and our results for EPG in fresh samples did not indicate any correlation between FLOTAC and McMaster. It is known that there is some interaction between the flotation
It is interesting that Sheather's solution seemed to be most efficient for fresh samples, but with preserved samples it showed a lower EPG than the sodium nitrate solution. The most suitable flotation solution for preserved samples was sodium nitrate with no difference in preservation methods used. Another advantage when examining frozen samples was that most of the strongyle eggs had not been destroyed in contrast to the situation with the preservation methods. This result is in contrast to other studies performed on sheep, where the majority of Haemonchus contortus eggs were damaged and EPG decreased after freezing $\left(-10^{\circ} \mathrm{C}\right.$ and $-170{ }^{\circ} \mathrm{C}$ in liquid nitrogen) for seven days (15). 
EPG of Ostertagia circumcincta decreased after freezing in $-10{ }^{\circ} \mathrm{C}(16)$.

Our results showed that SAF is not a suitable preservation reagent for equine faecal samples as indicated by the lowest strongyle EPG and Parascaris equorum egg values.

We tried to identify the most suitable preservation method for equine faecal samples as we were not aware of any previous publications on this topic. It is known that strongyles eggs are very fragile and should be examined within 48 hours of collection after being stored at fridge temperatures (17). This could be a problem when there are many samples from numerous herds. We tried various conservation methods which are used in human parasitology, such as freezing, preservation in formalin and SAF. Preservation in 5\% formalin produced more accurate results than other preservation methods (1). In general, it is advisable not to freeze faecal samples.

The latter paper showed that dog faecal samples preserved in 5\% formalin had a higher value of EPG when compared to those preserved in $10 \%$ formalin, SAF or frozen (9). A short communication (18) on the diagnosis of lungworm (Dictyocaulus filaria, Muellerius capillaris, Protostrongylus rufescens) in sheep using the FLOTAC apparatus reported that the highest faecal count was from samples preserved in 5\% formalin when compared with data from fresh samples and those preserved in $10 \%$ formalin or frozen. The results from our study indicate that samples preserved in 5\% formalin were very variable in both flotation solutions and in only one case EPG was higher than in a fresh sample.

Our results were unexpected because, in our study, freezing seemed to be the best preservation method for equine faecal samples in comparison with preservation in 5\% formalin or SAF. We anticipated that conditions of $-80^{\circ} \mathrm{C}$ would destroy most of the strongyle eggs and that the remaining eggs would be damaged. However, in defrosted samples, a minimum number of strongyle eggs were destroyed and a high EPG value was recorded in 10 out of 40 samples, the EPG count being higher than in fresh samples. This appears paradoxical but may be explained by the high aggregation of helminth eggs in faecal samples. To minimize the unequal distribution of eggs in faeces, careful homogenization of the samples is recommended. The finding that strongyle eggs "survive" such low temperatures is of great concern when considering the possibilities for elimination of strongyle eggs on grazing land. Further studies are required to discover if these "surviving" strongyle eggs would in fact be infective. An egg hatch assay would be useful.

\section{CONCLUSION}

Our study showed that the most suitable flotation solution for equine faecal samples seems to be Sheather's solution for fresh samples, but $\mathrm{NaNO}_{3}$ for preserved samples. The most efficient preservation method according to our results was freezing.

\section{ACKNOWLEDGEMENTS}

The study was supported by grant IGA VFU 41/2013/ FVL.

\section{REFERENCES}

1. Cringoli, G., Rinaldi, L., Maurelli, M. P., Utzinger, J. (2010). FLOTAC: new multivalent techniques for qualitative and quantitative compromicroscopic diagnosis of parasites in animals and humans. Nat. Protoc. 5, 503-515. http://dx.doi.org/10.1038/nprot.2009.235 PMid:20203667

2. Cringoli, G. (2006). FLOTAC, a novel apparatus for a multivalent faecal egg count technique. Vet. Parasitol. 48, 381-384.

3. Utzinger, J., Rinaldi, L., Lohouringnon, L. K., Rohner, F., Zimmermann, M. B., Rschannen, A. B., N'Goran, E. K. N., Cringoli, G. (2008). FLOTAC: a new sensitive technique for the diagnosis of hookworm infection in humans. Trans. R. Soc. Trop. Med. Hyg. 102, 84-90.

http://dx.doi.org/10.1016/j.trstmh.2007.09.009 PMid:18028969

4. Jeardon, A., Abdykdaueva, G., Usubalieva, J., Ensink, J. H. J., Cox, J., Matthys, B., Rinaldi, L., Cringoli, G., Utzinger, J.(2010). Accuracy of the Kato-Katz, adhesive tape and FLOTAC techniques for helminth diagnosis among children in Kyrgyzstan. Acta. Trop. 116, 185-192.

http://dx.doi.org/10.1016/j.actatropica.2010.08.010 PMid:20800568

5. Knopp, S., Speich, B., Hattendorf, J., Rinaldi, L., Mohammed, K. A., Khamis, I. S., Mohammed, A. S., Albonico, M., Rollinson, D., Marti, H., Cringoli, G., Utzinger, J. (2011). Diagnostic accuracy of Kato-Katz and FLOTAC for assessing anthelmintic drug efficacy. Plos. Negl. Trop. Dis. 4, e1036. http://dx.doi.org/10.1371/journal.pntd.0001036 PMid:21532740 PMCid:PMC3075226

6. Rinaldi, L., Veneziano, V., Morgoglione, M. E., Pennacchio, S., Santaniello, M., Schioppi, M., Musella, V., Fedele, V., Crignoli, G. (2009). Is gastrointestinal strongyle faecal egg count influenced by hour of sample collection and worm burden in goats? Vet. Parasitol. 163, 81-86.

http://dx.doi.org/10.1016/j.vetpar.2009.03.043

PMid:19414222 
7. Gaglio, G., Rinaldi, L., Brianti, E., Giannetto, S. (2008). Use of the FLOTAC technique for the diagnosis of Aelurostrongylus abstrusus in the cat. Parasitol. Res. 103, 1055-1057. http://dx.doi.org/10.1007/s00436-008-1091-4 PMid:18618146

8. Rinaldi, L., Calabri, G., Carbone, S., Carrella, A., Cringoli, G. (2007). Crenosoma vulpis in dog: first case report in Italy and use of the FLOTAC technique for copromicroscopic diagnosis. Parasitol. Res. 101, 1681-1684.

http://dx.doi.org/10.1007/s00436-007-0713-6 PMid:17805573

9. Cringoli, G., Rinaldi, L., Maurelli, M. P., Morgoline, M. E., Musella, V., Utzinger, J. (2011). Ancylostoma caninum: Calibration and comparison of diagnostic accuracy of flotation in tube, McMaster and FLOTAC in faecal samples of dogs. Experiment. Parasitol. 128, 32-37.

http://dx.doi.org/10.1016/j.exppara.2011.01.014 PMid:21295030

10. Schnyder, M., Maurelli, M. P., Morgoglione, M. E., Kohler, L., Deplazes, P., Torgerson, P., Cringoli, G., Rinaldi, L. (2011). Comparison of faecal techniques including FLOTAC for copromicroscopic detection of first stage larvae of Angiostrongylus vasorum. Parasitol. Res. 109, 63-69.

http://dx.doi.org/10.1007/s00436-010-2221-3 PMid:21181189

11. Cringoli, G., Rinaldi, L., Veneziano, V., Capelli, G., Scala, A. (2004). The influence of flotation solution, sample dilution and choise of McMaster technique in estimating the faecal egg counts of gastrointestinal strongyles and Dicrocoelium dendriticum in sheep. Vet. Parasitol. 123, 121-131.

http://dx.doi.org/10.1016/j.vetpar.2004.05.021 PMid:15265576

12. Rinaldi, L., Russo, T., Schioppi, M., Pennacchio, S., Cringoli, G. (2007). Passalurus ambiguus: new insights into copromicroscopic diagnosis and circadian rhythm of egg excretion. Parasitol. Res. 101, 557-561. http://dx.doi.org/10.1007/s00436-007-0513-z PMid:17372763
13. Levecke, B., De Wilde, N., Vandenhoute, E., Vercruysse, J. (2009). Field validity and feasibility of four techniques for the detection of Trichuris in simians: a model for monitoring drug efficacy in public health? PLos. Negl. Trop. Dis. 3, e366. http://dx.doi.org/10.1371/journal.pntd.0000366 PMid:19172171 PMCid:PMC2621347

14. Pietrzak-Johnston, S. M., Bishop, H., Walhquist, S., Moura, H., De Oliviera Da Silva, N., Pereira Da Silva, S., Nguyen-Dinh, P. (2000). Evaluation of commercially available preservatives for laboratory detection od Helminths and Protozoa in human fecal specimens. J. Clin. Microbiol. 38, 1959-1964. PMid:10790128; PMCid:PMC86633

15. Van Wyk, J., Wyk, L. (2002). Freezing of sheep faeces invalidates Haemonchus contortus faecal egg counts by the Mc Master technique. Onderstepoot J. Vet. Res. 69, 299-304.

PMid:12625382

16. Cabaret, J. (1981). Quantitative diagnostics of occurrence of small strongyle eggs and protostrongylides larvae in sheep. Effect of duration and selective method of preservation (in French: Diagnostic quantatif des oeufs de strongles digestifs et des larves de protostrongylides Cheb les ovins. Influence de la duree et du made de conservation des reces). Recueil de Medicine Vétérináre 157, 347-349.

17. Coles, G., Bauer, C., Borqsteede, F. H., Geerts, S., Klei, T. R., Taylor, M. A., Waller, P. J. (1992). World assessment of the advancement of veterinary parasitology (W.A.A.V.P.) methods for the detection of anthelmintic resistance in nematoda of veterinary importance. Vet. Parasitol. 44(1-2), 35-44. http://dx.doi.org/10.1016/0304-4017(92)90141-U

18. Rinaldi,L., Maurelli, M.P., Musella, V., Santaniello,A., Coles, G. C., Cringoli, G. (2010). FLOTAC: An improved method for diagnosis of lungworm infection in sheep. Vet. Parasitol. 169, 395-398. http://dx.doi.org/10.1016/j.vetpar.2010.01.008 PMid:20149543 